\title{
E- COMMERCE TANJAK MELAYU HASIL KERAJINAN TANGAN KELURAHAN AGROWISATA SEBAGAI UPAYA PROMOSI PASAR GLOBAL
}

\author{
Ira Puspita Sari ${ }^{1)}$, Eliya Mursyida ${ }^{2)}$, Reski Lestari ${ }^{3)}$ \\ 1) Program Studi Teknik Informatika Universitas Abdurrab \\ 2) Program Studi Pendidikan Dokter Universitas Abdurrab \\ 3) Program Studi Ilmu Pemerintahan Universitas Abdurrab \\ Email: ira.puspita.sari@univrab.ac.id, eliya.mursyida@univrab.ac.id, \\ reski.lestari@univrab.ac.id
}

\begin{abstract}
ABSTRAK
Tanjak merupakan hasil kerajinan tangan yang biasa dibuat oleh masyarakat melayu. Kelurahan Agrowisata memanfaatkan kerajinan tanjak sebagai penghasilan tambahan yang kemudian dipasarkan di pasar lokal. E-Commerce merupakan tempat jual beli secara dunia maya yang mana antara pembeli dan penjual tidak bertemu secara langsung melainkan melalui media sosial saja. Hasil kegiatan ini berupa akun instagram dan offical website yang menjadi sarana promosi hasil kerajinan tanjak Kelurahan Agrowisata.
\end{abstract}

Kata Kunci: Wesite, E-Commerce, Kerajinan Tangan, Promosi, Tanjak.

\section{ABSTRACT}

Tanjak is a handicraft that is usually made by Malay people. Kelurahan Agrowisata utilizes the uphill handicraft as an additional income which is then marketed in the local market. E-Commerce is a virtual buying and selling place where buyers and sellers do not meet in person but only through social media. The results of this activity in the form of an Instagram account and an offical website are a means of promotion of the results of the uphill handicraft in the Agrowisata Village.

Key words: Website, E-Commerce, Crafts, Promotion, Tanjak

\section{PENDAHULUAN}

Pada era globalisasi saat ini perkembangan internet semakin unggul bahkan dalam keseharian masyarakatpun menghabiskan waktunya dengan menggunakan internet, oleh karena itu untuk menyesuaikan dengan perkembangan zaman maka penulis ingin membantu warga Kelurahan Agrowisata di Kecamatan Rumbai dalam pembuatan web serta cara menggunakannya sehingga produk lokal dapat disebarkan dan dipasarkan melalui system elektronik seperti internet, atau yang lebih dikenal dengan istilah $e$ commerce. Saat ini produk lokal yang dihasilkan oleh warga Kelurahan Agrowisata hanya bersifat konvensional yang dipasarkan secara sederhana di rumah-rumah warga setempat saja, atau di pasar tradisional terdekat. Seiring perkembangan zaman, internet sebagai media informasi baru sudah mulai memasyarakat. Perkembangan teknologi dapat dimanfaatkan secara optimal dalam perdagangan di Indonesia. Melalui internet, warga dapat berhemat dengan memanfaatkan segala fasilitasnya dengan mudah, tentu hal ini sangat relevan untuk meningkatkan kemampuan daya saing dengan perusahaanperusahaan binis dalam penekanan biaya. 
E-Commerce merupakan media sosial yang pada umumnya digunakan sebagai sarana mempromosikan, bertransaksi, dan proses jual beli. Menurut Irmawati, Dewi, (2011) E-Commerce / Electronic Commerce merupakan kegiatan bisnis yang dijalankan (misalnya transaksi bisnis) secara elektronik melalui suatu jaringan (biasanya internet) dan komputer atau kegiatan jual beli barang atau jasa melalui jalur komunikasi digital". E-Commerce dapat memudahkan produsen atau usaha bisnis untuk mempromosikan jualannya kejangkauan yang lebih luas. Salah satu bentuk e-commerce adalah sosial media seperti instagram dan website. Zaman sekarang ini sudah banyak masyarakat menggunakan sosial media sebagai lahan mata pencarian baik dalam bentuk jasa atau barang. Tanjak merupakan kerajinan tangan khas daerah melayu yang biasa digunakan oleh raja-raja melayu pada zaman dahulu (Irmawati, 2011).

Merebaknya fasilitas internet diberbagai kalangan sehingga mengugah para pengusaha-pengusaha untuk meningkatkan pemasarannya secara online melalui media Internet, hal ini memungkinkan untuk memasarkan produk lokal yang mereka buat sehingga dapat dikenal oleh masyarakat luas. Hal ini yang membuat peneliti tertarik untuk membahasnya, sehingga mengangkat judul penelitian yaitu : E-commerce Tanjak Melayu Hasil Kerajinan Tangan Kelurahan Agrowisata Sebagai Upaya Promosi Pasar Global.

\section{TINJAUAN PUSTAKA}

\section{A. Definisi E-Commerce}

E-commerce merupakan suatu proses transaksi barang atau jasa melalui sistem informasi yang memanfaatkan teknologi informasi. Menurut Sutabri (2012) E-commerce adalah penyebaran, pembelian, penjualan, pemasaran barang dan jasa melalui sistem elektronik seperti internet atau televisi, www, atau jaringan komputer lainnya. $E$ commerce dapat melibatkan transfer dana elektronik, pertukaran data eletronik, sistem inventori otomatis dan sistem pengumpulan data otomatis. Sehingga dapat dikatakan bahwa e-commerce merupakan suatu pemasaran barang atau jasa melalui sistem informasi yang memanfaatkan teknologi (Sutabri, 2012).

\section{B. Manfaat E-commerce}

Manfaat dalam menggunakan E-commerce dalam suatu perusahaan sebagai sistem transaksi adalah:

a) Dapat meningkatkan market exposure (pangsa pasar): Transaksi on-line yang membuat semua orang di seluruh dunia dapat memesan dan membeli produk yang dijual hanya dengan melalui media computer dan tidak terbatas jarak dan waktu.

b) Menurunkan biaya operasional (operating cost): Transaksi E-commerce adalah transaksi yang sebagian besar operasionalnya diprogram di dalam komputer sehingga biaya-biaya seperti showroom, beban gaji yang berlebihan, dan lainlain tidak perlu terjadi.

c) Melebarkan jangkauan (global reach): Transaksi on-line yang dapat diakses oleh semua orang di dunia tidak terbatas tempat dan waktu karena semua orang dapat mengaksesnya hanya dengan menggunakan media perantara komputer.

d) Meningkatkan customer loyalty: Ini disebabkan karena sistem transaksi Ecommerce menyediakan informasi secara lengkap dan informasi tersebut dapat diakses setiap waktu dan dimana saja. 
e) Meningkatkan supply management: Transaksi E-commerce menyebabkan pengefisienan biaya operasional pada perusahaan terutama pada jumlah karyawan dan jumlah stok barang yang tersedia sehingga untuk lebih menyempurnakan pengefisienan biaya tersebut maka sistem supply management yang baik harus ditingkatkan.

\section{Sosial Media}

Kotler dan Keller (2016) mendefinisikan media sosial sebagai alat atau cara yang dilakukan oleh konsumen untuk membagikan informasi berupa teks, gambar, audio, dan video kepada orang lain dan perusahaan atau sebaliknya (Kotler and Keller, 2016). Dalam jurnal yang ditulis oleh Ekasari (2014), indikator yang digunakan dalam penelitian ini adalah relationship, komunikasi, interaksi pasca pembelian, format informasi (Ekasari, 2014).

Sosial media juga diartikan sebagai sebuah media untuk bersosialisasi satu sama lian dan dilakukan secara online yang memungkinkan manusia untuk saling berinteraksi tanpa dibatasi ruang dan waktu.

\section{Jasa/ Barang (tanjak)}

Melilitkan kain di kepala menjadi ciri khas kaum adam di daratan Melayu. Bentuk kain bisa beragam, seni melilitkannya juga cukup variatif. Kain yang dililitkan di kepala itu dinamakan Tanjak. Ibarat kaum pria Jawa memakai blangkon, sebagai simbol adat Jawa, yang sudah sangat populer di Indonesia. Keberadaan Tanjak di daratan Melayu juga sebagai ciri khas sejak bumi terbentang.

Pembuatan tanjak yang lebih berkreasi digagas oleh orang Melayu dahulu yang aktif di bidang gerak tangan. Kreasi yang muncul pada awalnya diberi nama tebing runtuh, belalai gajah, pial ayam, elang menyongsong angin dan lain sebagainya. Penamaan itu juga menyesuaikan bentuk tanjak yang dibuat. Sehingga sangat populer di dunia Melayu. (www.tribunpekanbaru.com)

\section{E. Promosi}

Menurut Lamb, Hair, Mc-Daniel (2014) promosi adalah komunikasi dari para penjual yang menginformasikan, membujuk, dan mengingatkan para calon pembeli suatu produk dalam rangka mempengaruhi pendapat mereka atau memperoleh suatu respon. Tujuan promosi menurut Kotler dan Armstrong (2009) yaitu :

a. Mendorong pembelian pelanggan jangka pendek atau meningkatkan hubungan pelanggan jangka panjang.

b. Mendorong pengecer menjual barang baru dan menyediakan lebih banyak persediaan.

c. Mengiklankan produk perusahaan dan memberikan ruang rak yang lebih banyak.

d. Untuk tenaga penjualan, berguna untuk mendapatkan lebih banyak dukungan tenaga penjualan bagi produk lama atau baru atau mendorong wiraniaga mendapatkan pelanggan baru (Lamb, Hair and McDaniel, 2014).

\section{METODE PELAKSANAAN}

Kegiatan ini dilaksanakan selama 7 hari dari tanggal 21 Juli s/d 27 Juli 2019 di Kelurahan Agrowisata. Pertama-tama tim melakukan survey dan silaturrahmi ke 
pengrajin tanjak gempita di Kelurahan Agrowisata, setelah itu tim melakukan wawancara mendalam terkait usaha tanjak milik warga sehingga mendapat bahan dan informasi untuk pembuatan website dan sosial media, kemudia tim melakukan membuatan sosial media dan website, serta memasukkan informasi-informasi umum terkait kerajinan tanjak di Kelurahan Agrowisata. Kegiatan ini dilaksanakan guna mempromosikan hasil kerajinan tanjak agar diketahui oleh pasar global.

\section{HASIL DAN PEMBAHASAN}

Kegiatan E-Commerce merupakan salah satu program kuliah kerja nyata kelompok satu kelurahan Agrowisata. Kegiatan ini baru pertama kali dilaksanakan di kelurahan Agrowisata. Mahasiswa KUKERTA memberikan website dan akun instagram kepada Kelurahan Agrowisata dan RW yang ada di Kelurahan Agrowisata. Kegiatan ini mendapatkan dukungan penuh dari Kelurahan Agrowisata dan masyarakat sekitar. Salah satu e-commerce yang telah dibuat adalah akun instagram (@desaagro2019) dan website (http://calculated-fuse.000webhostapp.com/index.php)

Selain itu pengusaha merasakan dampak yang positif Karena konsumen dapat mengetahui produk yang mereka tawarkan juga dapat meningkatkan penjualan melalui iklan yang mereka buat melalui media yang disediakan diinternet.

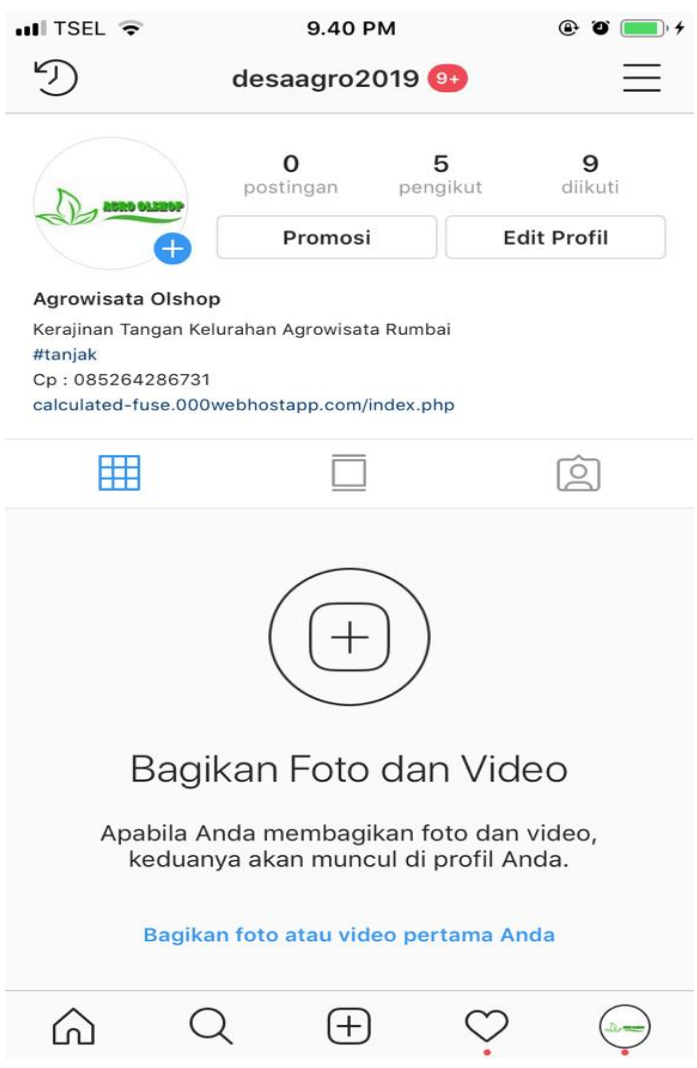

Gambar 1. Akun Instagram Agrowisata Online Shop 


\begin{tabular}{|c|c|c|c|}
\hline Q watile $\quad x$ & 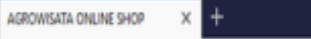 & & $-0 x$ \\
\hline$\leftarrow \rightarrow C \hat{\theta}$ & 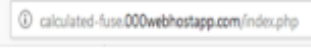 & $\ldots$.. 占 $Q$ sarch & $\ln \theta \equiv$ \\
\hline
\end{tabular}

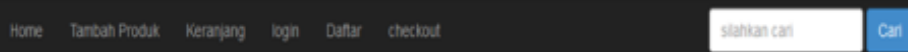

Produk Terbaru

Poweed by ie oc0methot

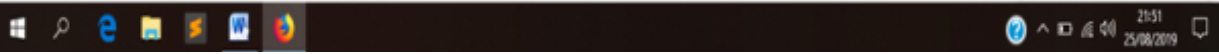

Gambar 2. Halaman Beranda Website Resmi Kelurahan Agrowisata

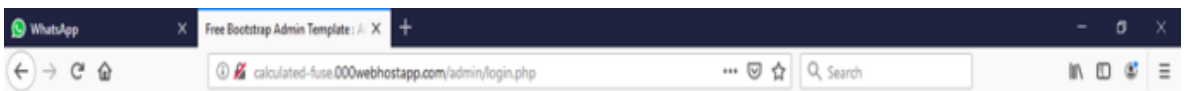

AGROWISATA ONLINE SHOP

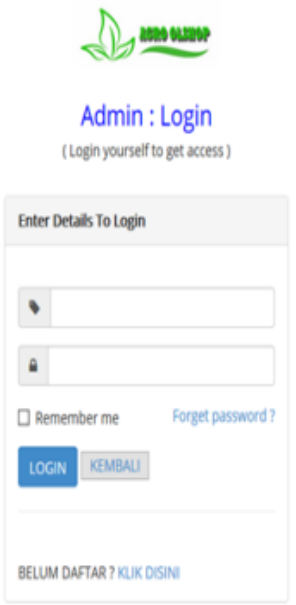

a $\rho$ e

Poweredy Re 000medost

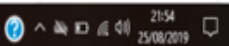

Gambar 3 . Halaman Login Website Resmi Kelurahan Agrowisata 


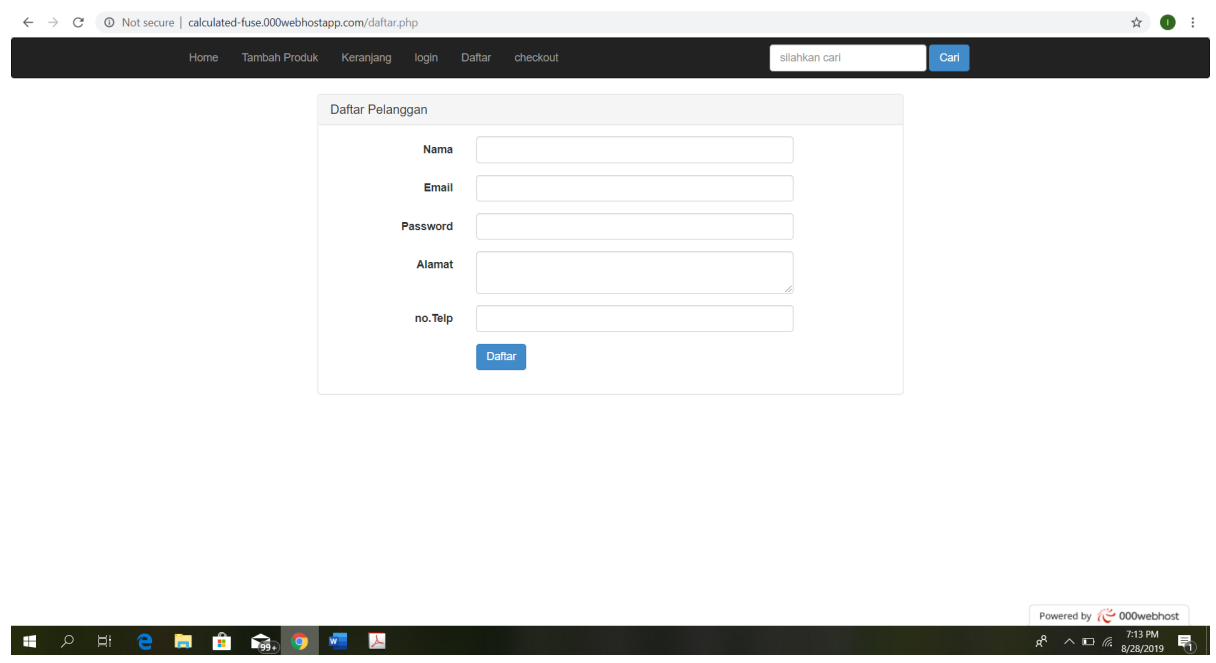

Gambar 4. Halaman Daftar Pelanggan Website Resmi Kelurahan Agrowisata

\section{KESIMPULAN}

Secara keseluruhan hasil kegiatan berjalan dengan lancar. Akun instagram dan website secara resmi telah di serahkan kepada masyarakat Kelurahan Agrowisata Kecamatan Rumbai yang memiliki usaha kerajinan tanjak. Bagi penyelenggara Kukerta berikutnya agar terus memantau dan meningkatkan fitur beserta kinerja akun instagram dan website tersebut. Pengusaha produk lokal memanfaatkan media internet dengan melakukan direct marketing terhadap produk-produk mereka di internet dengan memberikan penawaran khusus dan garansi terhadap produk yang telah terjual karena produk yang ditampilkan dalam website mereka terkadang tidak sesuai dengan harapan pembeli dengan cara menampilkan informasi mengenai penawaran khusus serta garansi dalam website yang dimiliki.

\section{DAFTAR PUSTAKA}

[1]. Ekasari, N. (2014) 'Pengaruh promosi berbasis sosial media terhadap keputusan pembelian produk jasa pembiayaan kendaraan pada PT. BFI Finance Jambi', Jurnal Penelitian Universitas Jambi: Seri Humaniora. Jambi University, 16(2).

[2]. Irmawati, D. (2011) 'Pemanfaatan e-commerce dalam dunia bisnis', Jurnal Ilmiah Orasi Bisnis-ISSN, 2085, p. 1375.

[3]. Kotler, P. and Keller, K. L. (2016) 'Marketing management (15th Global ed)', England: Pearson.

[4]. Lamb, C. W., Hair, J. F. and McDaniel, C. (2014) MKTG: Marketing. Cengage Learning.

[5]. Sutabri, T. (2012) Konsep Sistem Informasi. Penerbit Andi. 